\title{
ERRATUM
}

H.-W. Peng $\cdot$ C.-F. Chou $\cdot$ M.-S. Shiao $\cdot$ E. Lin

H.-J. Zheng • C. C. Chen - P. C. Fan

\section{Urine lipids in patients with a history of filariasis}

Urol Res (1997) 25:217-221

The publisher and the managing editor are sorry that on the first page of this paper the nationality of 6 of the 7 authors is incorrectly stated.

H.-W. Peng, C.-F. Chou, M.-S. Shiao, E. Lin, C. C. Chen and P. C. Fan are nationals of the Republic of China.
H.-W. Peng (四)

Department of Clinical Pathology, 804 Military General Hospital, Taoyuan, Taiwan, Republic of China

C.-F. Chou

Institute of Biomedical Sciences, Academia Sinica, Taipei, Taiwan, Republic of China

M.-S. Shiao - E. Lin

Department of Medical Research, Veterans General Hospital, Taipei, Taiwan, Republic of China

H.-J. Zheng

Guizhou Provincial Institute of Parasitic Diseases, People's

Republic of China

C. C. Chen - P. C. Fan

Department of Parasitology, School of Medicine, National YangMing University, Republic of China 